Womens Health Issues. 2014 ; 24(1): e89-e97. doi:10.1016/j.whi.2013.10.001.

\title{
Selected Preconception Health Indicators and Birth Weight Disparities in a National Study
}

\author{
Kelly L. Strutz, PhD, MPH ${ }^{a, b, c}$, Liana J. Richardson, PhD, MPH ${ }^{a, d}$, and Jon M. Hussey, PhD, \\ $\mathrm{MPH}^{\mathrm{a}, \mathrm{b}}$ \\ aCarolina Population Center, University of North Carolina at Chapel Hill \\ bDepartment of Maternal and Child Health, Gillings School of Global Public Health, University of \\ North Carolina at Chapel Hill \\ 'Department of Epidemiology and Biostatistics, College of Human Medicine, Michigan State \\ University \\ ${ }^{\mathrm{d} D e p a r t m e n t}$ of Sociology, University of North Carolina at Chapel Hill
}

\section{Abstract}

Background-This analysis explored the effect of timing, sequencing, and change in preconception health across adolescence and young adulthood on racial/ethnic disparities in birth weight in a diverse national cohort of young adult women.

Methods-Data came from Waves I (1994-1995), III (2001-2002), and IV (2007-2008) of the National Longitudinal Study of Adolescent Health. Eligibility was restricted to all singleton live births to female non-Hispanic White, non-Hispanic Black, Mexican-origin Latina, or Asian/Pacific Islander participants ( $\mathrm{n}=3014$ ) occurring between the Wave III (ages 18-26 years) and IV (ages 24-32 years) interviews. Birth weight was categorized into low ( $<2500$ grams), normal (25004000 grams), and macrosomic (>4000 grams). Preconception health indicators were cigarette smoking, heavy alcohol consumption, overweight or obesity, and inadequate physical activity, measured in adolescence (Wave I, ages 11-19 years) and early adulthood (Wave III) and combined into 4-category variables to capture the timing and sequencing of exposure.

Findings-Measures of preconception health did not explain the Black-White disparity in low birth weight, which increased after adjustment for confounders (odds ratio [OR] $=2.17,95 \%$ confidence interval [CI]: 1.33-3.53) and effect modification by overweight/obesity (OR=3.58, 95\%CI: 1.65-7.78). A positive association between adult-onset overweight/obesity and macrosomia was modified by race ( $\mathrm{OR}=3.83,95 \% \mathrm{CI}$ : $1.02-14.36$ for Black women).

(C) 2013 Jacobs Institute of Women's Health. Published by Elsevier Inc. All rights reserved.

Contact Information: Dr. Strutz (corresponding author): Telephone: 517-353-8623; kstrutz@epi.msu.edu, Mailing address: Michigan State University Department of Epidemiology and Biostatistics, 909 Fee Road Room B601, East Lansing, MI 48824, Fax:

517-432-1130.

Dr. Richardson: Telephone: 919-966-7481; 1jrichar@email.unc.edu.

Dr. Hussey: Telephone: 919-966-1731; jon_hussey@unc.edu.

Mailing address and fax number for Drs. Richardson and Hussey: Carolina Population Center, University of North Carolina at Chapel Hill, CB\# 8120, University Square, 123 W. Franklin St., Chapel Hill, NC 27516-2524., Fax: 919-966-6638.

Publisher's Disclaimer: This is a PDF file of an unedited manuscript that has been accepted for publication. As a service to our customers we are providing this early version of the manuscript. The manuscript will undergo copyediting, typesetting, and review of the resulting proof before it is published in its final citable form. Please note that during the production process errors may be discovered which could affect the content, and all legal disclaimers that apply to the journal pertain.

The authors report no financial conflicts of interest.

Related preliminary analyses were presented in June 2011 at the $3^{\text {rd }}$ National Summit on Preconception Health and Health Care, Tampa, FL, and at the annual meeting of the Society for Pediatric and Perinatal Epidemiologic Research, Montréal, QC. 
Conclusions-This longitudinal analysis provides new evidence on preconception health and racial/ethnic disparities in birth weight. Specifically, it indicates that interventions focused on prevention of overweight/obesity and maintenance of healthy weight during the transition to adulthood, especially among Black females, may be warranted.

\section{INTRODUCTION AND BACKGROUND}

As a predictor of both immediate and future morbidity and mortality (Henriksen, 2008; Mathews \& MacDorman, 2012; McCormick, 1985), birth weight is one of the most important indicators of population health. In particular, low birth weight (LBW) has been linked to poor motor development and future chronic disease risk (Barker, 2004; de Kieviet, Piek, Aarnoudse-Moens, \& Oosterlaan, 2009; Kanaka-Gantenbein, 2010) while high birth weight, or macrosomia, is associated with later overweight and obesity (Cnattingius et al., 2012; Mehta, Kruger, \& Sokol, 2011). Moreover, a reverse-J shaped association has been observed between the full range of birth weights and neonatal mortality; both LBW and macrosomic infants are at higher risk of mortality (Wilcox, 2001). Consequently, the persistence of large racial/ethnic disparities in birth weight in the U.S. (Martin et al., 2012) is particularly concerning. With mounting evidence that prenatal care may be too brief and come too late to mitigate risks for adverse birth outcomes that develop well before conception (Haas et al., 2005; Lu et al., 2003), the need to identify earlier contributors to disparities in birth weight is imperative.

By considering experiences and exposures over the entire life span, the life course perspective offers an ideal framework for approaching this task (Richardson, Hussey, \& Strutz, 2013). Consistent with this framework, the promotion of preconception health is increasingly viewed as a promising strategy to reduce adverse birth outcomes (Johnson et al., 2006; Misra \& Grason, 2006; Moos, 2006). Although the term "preconception" conveys a focus on reproduction (Wise, 2008), preconception health promotion has concentrated on indicators also shown to improve the overall health of reproductive-aged women (Moos, 2010). Evidence linking these indicators to birth outcomes, however, is limited. Thus, it remains unknown which preconception risks have the greatest impact on birth outcomes, and which ones contribute to racial/ethnic disparities in birth outcomes.

The life course principle of timing (Elder, 1994) reveals two other important gaps in our understanding. First, this principle suggests that we need to consider when preconception exposures occurred. Life course models allow for the possibility of critical or sensitive periods during which risk exposures may have a particularly strong impact on future health (Ben-Shlomo \& Kuh, 2002). For reproductive health, the period spanning adolescence and the transition to adulthood may be critical as this is the time when many health-impacting behaviors are established (Harris, 2010; Harris, Gordon-Larsen, Chantala, \& Udry, 2006). Second, the principle of timing calls attention to the potential importance of the sequencing of, duration of, and change in preconception exposures over time. Thus, the relative importance of exposures immediately before conception versus those earlier in life or throughout one's entire life may be meaningful. There is evidence, for example, that adultonset overweight — but not persistent overweight in adolescence and adulthood-increases the odds of delivering a macrosomic infant (Strutz, Richardson, \& Hussey, 2012).

Given large racial/ethnic differences in the prevalence and trajectories of leading health indicators during the transition to adulthood (Harris, Gordon-Larsen, Chantala, \& Udry, 2006), both dimensions of timing could be consequential for understanding how preconception health impacts birth outcome disparities. The few preconception studies that provide evidence on disparities (Haas et al., 2005; Hickey, Cliver, McNeal, \& Goldenberg, 1997; Johnson, Rottier, Luellwitz, \& Kirby, 2009; Simhan \& Bodner, 2006) produced 
inconsistent findings and were limited to health immediately before conception, rendering them incapable of evaluating how timing of preconception risk exposure impacts disparities. Moreover, three of the four studies focused on a single preconception health indicator (i.e., body mass index [BMI]).

We addressed these limitations in the present analysis and tested three specific hypotheses as conceptualized in Figure 1: 1) racial/ethnic differentials in levels of preconception health are an important contributor to racial/ethnic disparities in birth weight; 2) race/ethnicity and preconception indicators have direct effects on birth weight after controlling for prenatal factors; and 3) racial/ethnic differences in the strength of associations between preconception health and birth weight also contribute to the observed disparities in this outcome. We used data from the National Longitudinal Study of Adolescent Health (Add Health), which allowed us to examine multiple prospective indicators of preconception health, measured during adolescence and early adulthood, in a diverse national cohort of U.S. women.

\section{METHODS}

\section{Sample}

We used restricted-use data from Waves I, III, and IV of Add Health. Add Health is a prospective cohort study of a nationally representative probability sample of U.S. adolescents, who were in grades 7 through 12 (ages 11 -19) during the $1994-1995$ school year, followed into adulthood. From April to December of 1995, 20,745 adolescents completed a Wave I in-home interview (79\% response rate) and approximately $85 \%$ of their parents completed an interviewer-assisted questionnaire. In $2001-2002$ when respondents were ages $18-26,15,170$ Wave III in-home interviews were completed (77\% response rate). At Wave IV (2007 - 2008) in-home interviews were completed with 15,701 respondents aged $24-32$ years ( $80 \%$ response rate). Written informed consent was obtained from participants, or parents when participants were under age 18. Complete descriptions of the Add Health study design and sample are available elsewhere (Harris et al., 2009). All Add Health procedures and the present analysis were approved by the Public Health Institutional Review Board (IRB) at the University of North Carolina at Chapel Hill.

The sampling frame for the present analysis consisted of live births occurring between 42 weeks after Wave III and the Wave IV interview among female respondents who: selfidentified as non-Hispanic White, non-Hispanic Black, Mexican-Origin Latina, or Asian/ Pacific Islander; had valid sampling weights; and completed interviews at Waves I, III, and IV. We excluded live births of female respondents who were in other racial groups and Latina subgroups due to insufficient numbers for analysis $(n=403)$, and those who did not report their race/ethnicity $(n=19)$. We then excluded live births if they were plural $(n=140)$ or missing information on birth weight $(n=32)$. These exclusion criteria resulted in a final analytic sample of 3014 singleton live births among 2292 female respondents. The units of analysis were mother-infant dyads. The mean interval between the Wave III interview and birth was 1363 days (approximately 4 years).

\section{Measures}

Birth Weight-We obtained infants' birth weights from respondents' responses to the question "How much did \{baby's name \} weigh at birth?" at Wave IV, and converted them from pounds and ounces to grams. Birth weight was categorized into LBW (<2500 grams), normal (2500 - 4000 grams), or macrosomia (> 4000 grams [Adams, Alexander, Kirby, \& Wingate, 2009; Boulet, Alexander, Salihu, \& Pass, 2003]) to examine high-risk outcomes at both ends of the birth weight distribution. 
Preconception Health-Indicators of preconception health were chosen to reflect modifiable factors found in Healthy People 2020 objectives (U.S. Department of Health and Human Services, 2010) and clinical guidelines (Korenbrot, Steinberg, Bender, \& Newberry, 2002) for preconception care. Thus, they included: cigarette smoking, overweight or obesity, inadequate physical activity, and heavy alcohol consumption. These indicators were measured prospectively at Waves I (adolescence) and III (young adulthood). We combined the values for each indicator across the two waves to create a four-category variable (occurring at neither time point, in adolescence only, in young adulthood only, or at both time points) that captured timing, sequencing, and change in risk status over time.

Smoking was defined as any cigarette smoking during the past 30 days (Johnston, O'Malley, Bachman, \& Schulenberg, 2012; Substance Abuse and Mental Health Services

Administration, 2012). To determine overweight or obesity, we first calculated BMI (weight in kilograms divided by height in meters squared) from respondent height and weight (selfreported at Wave I and interviewer-measured at Wave III). Consistent with clinical standards, adolescent overweight/obesity was defined as reaching or exceeding the $85^{\text {th }}$ percentile for the age- and sex-specific Centers for Disease Control and Prevention (CDC) growth charts of BMI (Kuczmarski, et al., 2002), and adult overweight/obesity was defined as BMI $\geq 25 \mathrm{~kg} / \mathrm{m}^{2}$ (World Health Organization, 2000). We defined inadequate physical activity as participating in less than five bouts of moderate to vigorous physical activity in the past week, to approximate the U.S. guidelines for energy expenditure (Gordon-Larsen, Nelson, \& Popkin, 2004; Office of Disease Prevention and Health Promotion, 2008). We defined heavy alcohol consumption as consuming more than three drinks per day or more than seven drinks per week in the past year (National Institute on Alcohol Abuse and Alcoholism, 2004).

Prenatal factors-Prenatal covariates were measures of maternal cigarette smoking during pregnancy (yes/no), alcohol consumption during pregnancy (yes/no), and timing of entry into prenatal care (first trimester, second trimester, third trimester, or never) as reported by the respondent at Wave IV.

Potential Confounders-We included the following measures as potential confounders from a hypothesized causal model generated with DAGitty software (Textor, Hardt, \& Knuppel, 2011): respondent's age and parity (nulliparous/parous) at the time of the birth; nativity (foreign-born to foreign-born parent, native-born to foreign-born parent, or nativeborn to native-born parent); and two indicators of respondent's childhood socioeconomic status (SES) from both the respondent and the parent interviews: her mother's educational attainment (less than high school, general educational development certificate [GED], high school diploma, some college or trade school, or completed college or more), and any household receipt of public assistance before age 18 (yes/no).

\section{Statistical Analysis}

We examined variable distributions across the racial/ethnic categories using univariate and bivariate statistics, and used multinomial logistic regression to estimate the odds of LBW and macrosomia compared to normal birth weight for each racial/ethnic group with nonHispanic White as the referent category. We then used multiple multinomial logistic regression to obtain adjusted odds ratios (ORs) with 95\% confidence intervals (CIs) for LBW and macrosomia including the preconception health trajectories to evaluate whether inclusion of preconception indicators attenuated associations between race/ethnicity and birth weight. We used additional multiple multinomial logistic regression models to examine direct effects of race/ethnicity and preconception indicators controlling for potential confounders and prenatal factors. We then re-estimated models including interaction terms 
between race/ethnicity and the preconception indicators to determine effect modification of preconception health trajectories on birth weight. To maximize statistical power given the small sample sizes for some racial/ethnic groups, we included the potential confounders but not the prenatal factors in the latter models.

With the exception of birth weight and race/ethnicity, missing values on all covariates, which ranged from $<1 \%$ to $8 \%$, were imputed using multiple imputation. The findings were not sensitive to the use of imputed versus original data; we report the results for the imputed data here. We used Stata version 12 (StataCorp, College Station, TX) and accounted for Add Health's complex survey design and sampling weights by using the -svy- commands for all analyses. Before this accounting, sampling weights for respondents with more than one eligible birth in the analytic sample were divided equally among the births to account for autocorrelation; this method results in a pseudoweight similar to the sandwich estimators used in generalized estimating equations and other population-averaged models (Feng, McLerran, \& Grizzle, 1996; Zeger \& Liang, 1986).

\section{RESULTS}

\section{Sample Characteristics}

Non-White mothers had a higher prevalence of LBW infants than non-Hispanic White mothers, with the highest prevalence among non-Hispanic Black mothers. In contrast, macrosomia was most prevalent among non-Hispanic White infants. These findings and other descriptive characteristics of the sample are shown in Table 1. Demographic characteristics varied by race/ethnicity, with higher percentages of Mexican-origin Latinas and Asian/Pacific Islanders reporting first- or second-generation immigrant status, and with Blacks and Latinas overrepresented among lower childhood SES origins.

Preconception health risks were common at both time points, and differed across racial/ ethnic group as well. Non-Hispanic White women had the highest prevalence of substance use, although Mexican-origin Latinas had approximately equal percentages of smoking in adolescence or drinking heavily in adulthood. Latinas had the highest prevalence of adultonset overweight/obesity while non-Hispanic Black women had the highest prevalence of persistent overweight/obesity. Asian/Pacific Islander women had the lowest prevalence of preconception alcohol use and overweight. Inadequate physical activity was common across time points for all racial/ethnic groups. Prenatal smoking was most common among Whites while prenatal alcohol use was most common among Latinas and Asians. The majority of women entered prenatal care in their first trimester but Asian women had the highest prevalence of receiving no prenatal care.

\section{Multivariate Results}

Tables 2 and 3 present the multinomial logistic regression results for the relationship between race/ethnicity, preconception health, and the odds of LBW and macrosomia versus normal birth weight, with the LBW results from these models shown in Table 2 and the corresponding macrosomia results from the same models shown in Table 3. In Table 2, Model 1, we found that non-Hispanic Blacks were nearly twice as likely to deliver a LBW infant versus a normal birth weight infant than non-Hispanic Whites $(\mathrm{OR}=1.91$; 95\%CI: 1.25-2.90). The odds of LBW among respondents in other racial/ethnic groups was not significantly different from Whites. Adding the preconception health indicators to the model (Model 2) did not impact the results for race/ethnicity substantially, despite a strong effect of overweight/obesity in adolescence ( $\mathrm{OR}=3.42 ; 95 \% \mathrm{CI}$ : 1.04-11.24). However, when we introduced the potential confounders to the model (Model 3), the odds of LBW for nonHispanic Blacks compared to Whites increased (OR $=2.17$; 95\%CI: 1.33-3.53). Introducing 
prenatal factors into the model (Model 4) changed this increase only slightly. Thus, in the fully adjusted model, Blacks were over twice as likely to deliver a LBW versus normal birth weight infant than Whites ( $\mathrm{OR}=2.16$; 95\%CI: 1.31-3.56). The strong relationship with adolescent overweight/obesity was no longer statistically significant after inclusion of confounders. In addition, none of the other preconception health indicators was significantly associated with LBW in any of the Table 2 models.

Table 3 presents the odds of macrosomia versus normal birth weight for the multinomial logistic regression results. In Model 1, we found that Asian/Pacific Islanders were $71 \%$ less likely to deliver a macrosomic versus normal birth weight infant than Whites $(\mathrm{OR}=0.29$; 95\%CI: 0.14-0.58). The odds of macrosomia among respondents in other racial/ethnic groups was not significantly different from Whites. Adding the preconception health indicators to the model (Model 2) had little impact on the results for race/ethnicity. However, preconception overweight/obesity emerged as the only preconception health indicator to be significantly associated with macrosomia. Specifically, adult-onset overweight/obesity was associated with a $69 \%$ greater odds of delivering a macrosomic versus normal birth weight infant $(\mathrm{OR}=1.69 ; 95 \% \mathrm{CI}$ : 1.10-2.60). When we introduced the potential confounders to the model (Model 3), the association between Asian/Pacific Islanders and macrosomia became non-significant, and the addition of prenatal health factors did not alter these results (Model 4). Thus, in the fully adjusted model, there appears to be no association between race/ethnicity and the odds of macrosomia versus normal birth weight.

These pooled sample results could mask important racial/ethnic differences in covariate effects; therefore we estimated adjusted models with interaction terms focusing specifically on overweight/obesity because of its emergence as a key predictor in Tables 2 and 3 . As Table 4 shows, the statistically significant associations between overweight/obesity and birth weight that we previously found were modified by race/ethnicity. In particular, the BlackWhite disparity in LBW was magnified after controlling for effect modification (OR=3.58, 95\%CI: 1.65-7.78) with a significant protective interaction between Black race and overweight/obesity at both time points ( $\mathrm{OR}=0.27,95 \% \mathrm{CI}: 0.08-0.99)$. Conversely, the association between adult-onset overweight/obesity and macrosomia was no longer significant after accounting for effect modification, and was strongest for Black women (interaction $\mathrm{OR}=3.83,95 \% \mathrm{CI}: 1.02-14.36$ ).

\section{CONCLUSIONS AND DISCUSSION}

The present analysis applied a life course perspective and utilized longitudinal, nationally representative data to extend our knowledge of the link between preconception health indicators and birth outcome disparities. By examining preconception health risks at two time points, we were able to evaluate both adolescence and young adulthood as potential critical or sensitive periods during which preconception exposures can affect infant health disparities. In addition, this measurement strategy allowed us to examine the effects of stability and change in prepregnancy exposures. Our analysis used data from a national prospective cohort, and thus mitigated biases (e.g., recall bias, selection bias, and lack of generalizability) common to research involving samples from prenatal clinics or reliant on retrospective reports of preconception factors. Furthermore, our analyses included Mexicanorigin Latinas and Asian/Pacific Islanders-two racial/ethnic groups that are underrepresented in the literature on birth outcome disparities - offering the opportunity to examine the factors that contribute to disparities and the relative importance of the factors across groups. Finally, unlike most studies of birth weight disparities that focus on low birth weight, we examined births at both extremes of the weight distribution. 
We found a Black-White disparity in LBW that was not explained by this set of modifiable preconception health indicators, and increased after adjustment for possible confounders and effect modification. This finding is consistent with previous studies that have generated little explanation for the Black-White disparity in LBW when prenatal risk factors are examined (e.g., Goldenberg et al., 1996); our findings suggest that this set of modifiable preconception health indicators has limited explanatory power as well. With respect to previous studies of the role of preconception BMI or health behaviors, our findings were somewhat consistent with a study of PTB disparities in Missouri (Johnson, Rottier, Luellwitz, \& Kirby, 2009). In this study, controlling for preconception overweight or obesity, preconception or gestational diabetes, and other prenatal factors increased the Black-White disparity. However, our results were less consistent with a California study (Haas et al., 2005), in which adjusting for preconception factors (including BMI, smoking, and exercise) attenuated the Black-White disparity in PTB.

Our analysis also provides new evidence on racial/ethnic differences in macrosomic births. Specifically, an advantage for infants of Asian mothers as compared to those of White mothers was no longer significant after introducing confounders into the models, suggesting that much of the Asian-White difference in macrosomia is spurious. Infants of Black and Latina mothers did not have significantly different odds of macrosomia from those of White mothers, a noteworthy finding given the higher prevalence of predictors of macrosomia, including obesity (Harris, Gordon-Larsen, Chantala, \& Udry, 2006) and gestational diabetes (Hedderson, Darbinian, \& Ferrara, 2010), among Black and Latina women. Although the disparity in preconception overweight/obesity for Blacks and Latinas was evident in our analysis, we could not examine the roles of inadequate weight gain or gestational diabetes with these data. Finally, the overall association between adult-onset overweight/obesity and macrosomia, consistent with previous research (Strutz, Richardson, \& Hussey, 2012), was modified by race such that it was stronger for Black women. This finding is complementary to studies of PTB in which strong associations between underweight preconception BMI and PTB were identified for Black women (Hickey, Cliver, McNeal, \& Goldenberg, 1997; Simhan \& Bodnar, 2006).

\section{Limitations}

Several limitations should be noted. Our preconception health indicators were measured at just two time points - in adolescence and again approximately seven years later in early adulthood - and thus provide a less complete portrait of preconception health trajectories than could be constructed with more frequent and more closely spaced measures.

Additionally, while our focus was on leading health indicators as identified by Healthy People 2020, other preconception risk factors are likely of greater importance. With respect to these indicators, adolescent BMI was calculated from self-reported height and weight; however, these measures have been demonstrated to be reliable in Add Health respondents particularly when categorizing BMI (Goodman, Hinden, \& Khandelwal, 2000).

Further, our interest in using longitudinal measures of preconception health dictated our focus on births to women ages 18-32. Although women in this age group account for the majority of all US births each year (Martin et al., 2012), our findings may not generalize to births at younger or older maternal ages. The dataset also does not include comprehensive pregnancy information. We acknowledge that birth weight is not necessarily a cause of adverse health outcomes (Wilcox, 2001), but remains valuable as the most accessible marker of fetal development (Currie \& Moretti, 2007). Birth weight was assessed using maternal recall rather than clinical report, but maternal report of birth weight has been validated in previous studies (Adegboye \& Heitmann, 2008; Walton et al., 2000). In addition, racial/ ethnic disparities in birth weight in Add Health are consistent with expectations from vital 
statistics (Martin et al., 2012). Lack of gestational age data precluded examination of subtypes of low and high birth weight, e.g., post-term macrosomia vs. macrosomia due to large-for-gestational age. Moreover, macrosomia can be defined in other ways (e.g., as weight $>4500 \mathrm{~g}$ or $>5000 \mathrm{~g}$ [Adams, Alexander, Kirby, \& Wingate, 2009; Boulet, Alexander, Salihu, \& Pass, 2003]), and risks may differ for racial/ethnic groups, including Blacks and Asians, whose birth weight distributions are shifted to the left compared to those of Whites (Martin et al., 2012). However, due to the differences in overall birth weight distributions, our use of a lower cutoff point correctly classifies more Black and Asian infants as macrosomic. In addition, the dataset lacked measures of prenatal health status including gestational diabetes, hypertension, and other pregnancy complications that affect infant size, and thus we could not examine the role of these factors in mediating or moderating racial/ ethnic differences in the relationships between preconception factors and birth weight.

Finally, our effect modification analyses were limited by smaller sample sizes for the nonWhite racial/ethnic groups. For example, there were too few births among Asian women to include them. Similarly, sparse data did not allow us to include all covariates from the pooled regression models in our modification models. Rather, we decided to focus on preconception obesity status, which emerged as the most important prepregnancy risk factor in the pooled model.

\section{Implications for Practice and Policy}

Using prospective longitudinal data to explore the role of timing, sequencing, and change in preconception risk status across adolescence and adulthood, this analysis advances our understanding of how prepregnancy health influences racial/ethnic disparities in birth outcomes and contributes to the ongoing discourse about applying a life course perspective to research on perinatal health disparities (Richardson, Hussey, \& Strutz, 2013). In addition, because preconception care recommendations have been made largely without evidence of their utility in reducing adverse birth outcomes, our analysis informs recent calls for a focus on preconception health. Specifically, our analysis indicates that the traditional indicators of pregnancy risk are likely not the most salient factors in the preconception period, and supports recent efforts to identify and assess life course measures across broader domains (Association of Maternal and Child Health Programs, 2013). However, this work also suggests that interventions may be most effective in reducing adverse birth outcomes if focused on prevention of overweight/obesity and maintenance of healthy weight during the transition to adulthood, especially among non-Hispanic Black females. Future research using data collected at multiple time points, beginning in early childhood, will assist in further identifying the ideal time at which to initiate such interventions. Likewise, it may reveal that smoking, drinking and physical activity do play a role in adverse birth outcomes, but at a time or for a duration not captured by our analysis. It is worth noting that the measured risk factors have been shown to increase women's propensity for later chronic disease. Thus, interventions targeting these factors could be critical for women's health more generally. Continued investments in prospective longitudinal datasets will prove essential for these and other preconception health-related efforts.

\section{Acknowledgments}

This research was supported by the Eunice Kennedy Shriver National Institute of Child Health \& Human Development at the National Institutes of Health (grant numbers R01-HD057073, R01-HD058535, T32HD052468, and T32-HD046377). The authors are grateful to the Carolina Population Center (R24-HD050924) for general support. Kelly Strutz had full access to all of the data in the study and takes responsibility for the integrity of the data and the accuracy of the data analysis. This research uses data from Add Health, a program project directed by Kathleen Mullan Harris and designed by J. Richard Udry, Peter S. Bearman, and Kathleen Mullan Harris at the University of North Carolina at Chapel Hill, and funded by a grant P01-HD31921 from the Eunice Kennedy Shriver National Institute of Child Health and Human Development, with cooperative funding from 23 
other federal agencies and foundations. Special acknowledgment is due Ronald R. Rindfuss and Barbara Entwisle for assistance in the original design. Information on how to obtain the Add Health data files is available on the Add Health website (http://www.cpc.unc.edu/addhealth). No direct support was received from grant P01-HD31921 for this analysis. The authors would like to thank Chirayath Suchindran for assistance with statistical analysis, as well as Milton Kotelchuck and four anonymous reviewers for comments on earlier versions of the manuscript.

\section{REFERENCES}

Adams, MM.; Alexander, GR.; Kirby, RS.; Wingate, MS. Perinatal epidemiology for public health practice. New York: Springer Science+Business Media; 2009.

Adegboye ARA, Heitmann BL. Accuracy and correlates of maternal recall of birthweight and gestational age. British Journal of Obstetrics and Gynaecology. 2008; 115:886-893. [PubMed: 18485168]

Association of Maternal and Child Health Programs. Life Course Metrics Project 2012-2013. 2013. Retrieved September 4, 2013 from http://www.amchp.org/programsandtopics/data-assessment/ projects/Pages/LifeCourseMetrics.aspx.

Barker DJ. The developmental origins of adult disease. Journal of the American College of Nutrition. 2004; 23(suppl) 588s-595s.

Ben-Shlomo Y, Kuh D. A life course approach to chronic disease epidemiology: conceptual models, empirical challenges and interdisciplinary perspectives. International Journal of Epidemiology. 2002; 31:285-293. [PubMed: 11980781]

Boulet SL, Alexander GR, Salihu HM, Pass M. Macrosomic births in the United States: determinants, outcomes, and proposed grades of risk. American Journal of Obstetrics and Gynecology. 2003; 188:1372-1378. [PubMed: 12748514]

Cnattingius S, Villamor E, Lagerros YT, Wikstrom AK, Granath F. High birth weight and obesity - a vicious circle across generations. International Journal of Obesity. 2012; 36:1320-1324. [PubMed: 22158263]

Currie J, Moretti E. Biology as destiny? Short- and long-run determinants of intergenerational transmission of birth weight. Journal of Labor Economics. 2007; 25:231-263.

de Kieviet JF, Piek JP, Aarnoudse-Moens CS, Oosterlaan J. Motor development in very preterm and very low-birth-weight children from birth to adolescence. JAMA. 2009; 302:2235-2242. [PubMed: 19934425]

Elder GH. Time, human agency, and social change: perspectives on the life course. Social Psychology Quarterly. 1994; 57:4-15.

Feng Z, McLerran D, Grizzle J. A comparison of statistical methods for clustered data analysis with Gaussian error. Statistics in Medicine. 1996; 15:1793-1806. [PubMed: 8870161]

Goldenberg RL, Cliver SP, Mulvihill FX, Hickey CA, Hoffman HJ, Klerman LV, Johnson MJ. Medical, psychosocial, and behavioral risk factors do not explain the increased risk for low birth weight among black women. American Journal of Obstetrics and Gynecology. 1996; 175:13171324. [PubMed: 8942508]

Goodman E, Hinden BR, Khandelwal S. Accuracy of teen and parental reports of obesity and body mass index. Pediatrics. 2000; 106:52-58. [PubMed: 10878149]

Gordon-Larsen P, Nelson MC, Popkin BM. Longitudinal physical activity and sedentary behavior trends: adolescence to adulthood. American Journal of Preventive Medicine. 2004; 27:277-283. [PubMed: 15488356]

Haas JS, Fuentes-Afflick E, Stewart AL, Jackson RA, Dean ML, Brawarsky P, et al. Prepregnancy health status and the risk of preterm delivery. Archives of Pediatrics and Adolescent Medicine. 2005; 159:58-63. [PubMed: 15630059]

Harris KM. An integrative approach to health. Demography. 2010; 47:1-22. [PubMed: 20355681]

Harris KM, Gordon-Larsen P, Chantala K, Udry JR. Longitudinal trends in race/ethnic disparities in leading health indicators from adolescence to young adulthood. Archives of Pediatrics and Adolescent Medicine. 2006; 160:74-81. [PubMed: 16389215]

Harris, KM.; Halpern, CT.; Whitsel, EA.; Hussey, J.; Tabor, J.; Entzel, P., et al. The National Longitudinal Study of Adolescent Health: research design. 2009. Retrieved September 4, 2013, from http://www.cpc.unc.edu/projects/addhealth/design. 
Hedderson MM, Darbinian JA, Ferrara A. Disparities in the risk of gestational diabetes by raceethnicity and country of birth. Paediatric and Perinatal Epidemiology. 2010; 24:441-448. [PubMed: 20670225]

Henriksen T. The macrosomic fetus: a challenge in current obstetrics. Acta Obstetricia et Gynecologia Scandinavica. 2008; 87:134-145.

Hickey CA, Cliver SP, McNeal SF, Goldenberg RL. Low pregravid body mass index as a risk factor for preterm birth: variation by ethnic group. Obstetrics and Gynecology. 1997; 89:206-212. [PubMed: 9015021]

Johnson K, Posner SF, Biermann J, Cordero JF, Atrash HK, Parker CS, et al. Recommendations to improve preconception health and health care--United States. A report of the CDC/ATSDR Preconception Care Work Group and the Select Panel on Preconception Care. Morbidity and Mortality Weekly Report Recommendations and Reports. 2006; 55:1-23. [PubMed: 16617292]

Johnson TS, Rottier KJ, Luellwitz A, Kirby RS. Maternal prepregnancy body mass index and delivery of a preterm infant in Missouri 1998-2000. Public Health Nursing. 2009; 26:3-13. [PubMed: 19154188]

Johnston, LD.; O'Malley, PM.; Bachman, JG.; Schulenberg, JE. Monitoring the Future national survey results on drug use, 1975-2011. Volume I: Secondary school students and Volume II: College students and adults ages 19-50. Ann Arbor, MI: Institute for Social Research, The University of Michigan; 2012.

Kanaka-Gantenbein C. Fetal origins of adult diabetes. Annals of the New York Academy of Sciences. 2010; 1205:99-105. [PubMed: 20840260]

Korenbrot CC, Steinberg A, Bender C, Newberry S. Preconception care: a systematic review. Maternal and Child Health Journal. 2002; 6:75-88. [PubMed: 12092984]

Kuczmarski RJ, Ogden CL, Guo SS, Grummer-Strawn LM, Flegal KM, Mei Z, et al. 2000 CDC growth charts for the United States: methods and development. Vital Health Statistics. 2002; 246:1-190. [PubMed: 12043359]

Lu MC, Tache V, Alexander GR, Kotelchuck M, Halfon N. Preventing low birth weight: is prenatal care the answer. The Journal of Maternal-Fetal and Neonatal Medicine. 2003; 13:362-380. [PubMed: 12962261]

Martin JA, Hamilton BE, Ventura SJ, Osterman JK, Wilson EC, Mathews TJ. Births: final data for 2010. National Vital Statistics Reports. 2012; 61:1-100.

Mathews TJ, MacDorman MF. Infant mortality statistics from the 2008 period linked birth/infant death data set. National Vital Statistics Reports. 2012; 60:1-28. [PubMed: 22670489]

McCormick MC. The contribution of low birth weight to infant mortality and childhood morbidity. New England Journal of Medicine. 1985; 312:82-90. [PubMed: 3880598]

Mehta SH, Kruger M, Sokol RJ. Being too large for gestational age precedes childhood obesity in African Americans. American Journal of Obstetrics and Gynecology. 2011; 204:265.e1-265.e5. [PubMed: 21376166]

Moos MK. Preconception health: where to from here. Women's Health Issues. 2006; 16:156-158. [PubMed: 16920520]

Moos MK. From concept to practice: reflections on the preconception health agenda. Journal of Women's Health. 2010; 19:561-567.

Misra DP, Grason H. Achieving safe motherhood: applying a life course and multiple determinants perinatal framework in public health. Women's Health Issues. 2006; 16:159-175. [PubMed: 16920521]

National Institute on Alcohol Abuse and Alcoholism. Helping patients with alcohol problems: a health practitioner's guide. Bethesda, MD: National Institutes of Health; 2004.

Office of Disease Prevention and Health Promotion. Physical activity guidelines for Americans. Washington, DC: US Department of Health and Human Services; 2008.

Richardson, LJ.; Hussey, JM.; Strutz, KL. A life course perspective on maternal and child health. In: Kotch, JB., editor. Maternal and child health: programs, problems, and policy in public health. 3rd ed. Sudbury, MA: Jones and Bartlett Publishers; 2013. p. 65-85.

Simhan H, Bodnar L. Prepregnancy body mass index, vaginal inflammation, and the racial disparity in preterm birth. American Journal of Epidemiology. 2006; 163:459-466. [PubMed: 16394203] 
Strutz KL, Richardson LJ, Hussey JM. Preconception health trajectories and birth weight in a national prospective cohort. Journal of Adolescent Health. 2012; 51:629-636. [PubMed: 23174475]

Substance Abuse and Mental Health Services Administration. Results from the 2011 National Survey on Drug Use and Health: summary of national findings, NSDUH Series H-44, HHS Publication No. (SMA) 12-4713. Rockville, MD: Substance Abuse and Mental Health Services Administration; 2012.

Textor J, Hardt J, Knuppel S. DAGitty: a graphical tool for analyzing causal diagrams. Epidemiology. 2011; 22:745. [PubMed: 21811114]

US Department of Health and Human Services Office of Disease Prevention and Health Promotion. Healthy People 2020. 2010. Retrieved September 4, 2013 from http://www.healthypeople.gov

Walton KA, Murray LJ, Gallagher AM, et al. Parental recall of birthweight: a good proxy for recorded birthweight. European Journal of Epidemiology. 2000; 16:793-796. [PubMed: 11297220]

Wilcox AJ. On the importance - and the unimportance - of birth weight. International Journal of Epidemiology. 2001; 30:1233-1241. [PubMed: 11821313]

Wise PH. Transforming preconceptional, prenatal, and interconceptional care into a comprehensive commitment to women's health. Women's Health Issues. 2008; 18(suppl):s13-s18. [PubMed: 18951817]

World Health Organization. Obesity: preventing and managing the global epidemic: report of a WHO consultation. World Health Organization Technical Report Series. 2000; 894:1-253.

Zeger SL, Liang KY. Longitudinal data analysis for discrete and continuous outcomes. Biometrics. 1986; 42:121-130. [PubMed: 3719049] 


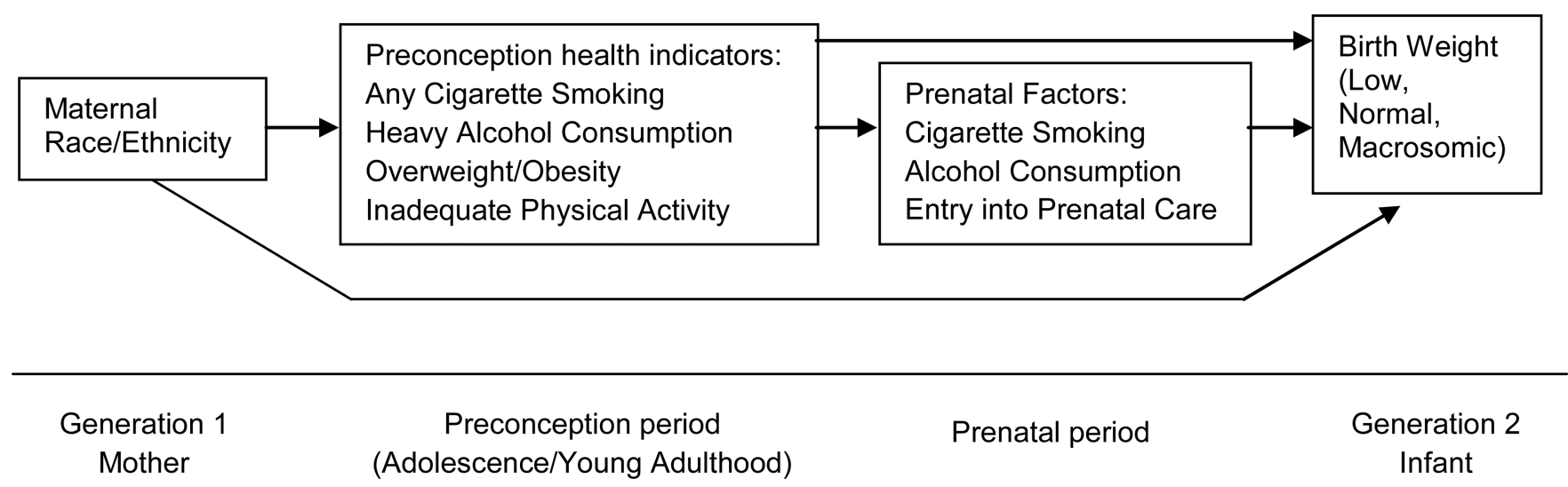

Figure 1.

Conceptual model depicting hypothesized relationships among race/ethnicity, preconception health indicators, prenatal factors, and birth weight, National Longitudinal Study of Adolescent Health, 1994-2008. 
Table 1

Characteristics of the Study Population, National Longitudinal Study of Adolescent Health, 1994-2008

\begin{tabular}{|c|c|c|c|c|c|}
\hline \multirow[b]{2}{*}{ Characteristic } & \multicolumn{4}{|c|}{ Racial/Ethnic Group } & \multirow[b]{2}{*}{$\left(\mathrm{n}=\begin{array}{r}\text { Total } \\
\mathbf{3 0 1 4})\end{array}\right.$} \\
\hline & $\begin{array}{r}\text { Non- } \\
\text { Hispanic } \\
\text { White } \\
(\mathbf{n}=\mathbf{1 8 6 3})\end{array}$ & $\begin{array}{r}\text { Non- } \\
\text { Hispanic } \\
\text { Black } \\
(\mathrm{n}=\mathbf{6 9 8})\end{array}$ & $\begin{array}{r}\text { Mexican- } \\
\text { Origin } \\
\text { Latina } \\
(\mathbf{n}=\mathbf{3 0 7})\end{array}$ & $\begin{array}{r}\text { Asian/Pacific } \\
\text { Islander } \\
(\mathbf{n}=\mathbf{1 4 6})\end{array}$ & \\
\hline \multicolumn{6}{|l|}{ Birth Weight, \% } \\
\hline LBW & 7.0 & 12.9 & 8.0 & 8.3 & 8.1 \\
\hline Normal & 82.2 & 79.4 & 84.4 & 88.4 & 82.1 \\
\hline Macrosomia & 10.8 & 7.7 & 7.6 & 3.3 & 9.8 \\
\hline \multicolumn{6}{|l|}{ Demographic Confounders } \\
\hline Age, mean (SE), y & $26.1(0.2)$ & $25.6(0.3)$ & $26.0(0.4)$ & $27.2(0.4)$ & $26.0(0.1)$ \\
\hline \multicolumn{6}{|l|}{ Parity, \% } \\
\hline Nulliparous & 57.3 & 33.9 & 43.3 & 61.4 & 52.3 \\
\hline Parous & 42.7 & 66.1 & 56.7 & 38.6 & 47.7 \\
\hline \multicolumn{6}{|l|}{ Nativity, $\%$} \\
\hline Foreign-born to foreign-born parent & 0.3 & 1.0 & 18.3 & 47.0 & 3.1 \\
\hline Native-born to foreign-born parent & 3.2 & 2.6 & 42.7 & 33.7 & 7.0 \\
\hline Native-born to native-born parent & 96.4 & 96.2 & 39.0 & 19.3 & 89.8 \\
\hline \multicolumn{6}{|l|}{ Childhood SES } \\
\hline \multicolumn{6}{|l|}{ Mother's Educational Attainment, $\%$} \\
\hline Less than high school & 12.4 & 23.8 & 57.9 & 35.6 & 18.5 \\
\hline GED & 5.7 & 3.7 & 3.9 & 2.6 & 5.1 \\
\hline High school diploma & 33.2 & 35.7 & 18.5 & 13.8 & 32.0 \\
\hline Some college or trade school & 30.4 & 23.8 & 12.0 & 17.7 & 27.5 \\
\hline Completed college or more & 18.3 & 13.6 & 8.2 & 30.2 & 17.0 \\
\hline Any Household Receipt of Public Assistance, \% & 30.0 & 52.8 & 32.0 & 27.5 & 34.0 \\
\hline \multicolumn{6}{|l|}{ Preconception Health Indicators } \\
\hline \multicolumn{6}{|l|}{ Any Cigarette Smoking } \\
\hline Neither time point & 44.7 & 77.9 & 70.9 & 77.4 & 53.3 \\
\hline Adolescence only & 11.8 & 6.2 & 12.1 & 3.9 & 10.7 \\
\hline Adulthood only & 18.1 & 10.4 & 9.0 & 11.1 & 15.9 \\
\hline Both time points & 25.3 & 5.4 & 7.6 & 7.6 & 20.1 \\
\hline \multicolumn{6}{|l|}{ Heavy Alcohol Consumption } \\
\hline Neither time point & 49.2 & 78.0 & 60.3 & 81.4 & 55.9 \\
\hline Adolescence only & 15.9 & 7.7 & 10.4 & 3.8 & 13.7 \\
\hline Adulthood only & 23.3 & 12.1 & 22.5 & 10.2 & 21.0 \\
\hline Both time points & 11.6 & 2.2 & 6.8 & 4.5 & 9.4 \\
\hline \multicolumn{6}{|l|}{ Overweight/Obesity } \\
\hline Neither time point & 53.6 & 36.4 & 38.4 & 79.4 & 50.2 \\
\hline Adolescence only & 0.9 & 1.5 & 2.3 & 0.0 & 1.1 \\
\hline Adulthood only & 30.5 & 33.7 & 39.9 & 11.2 & 31.3 \\
\hline Both time points & 15.3 & 28.5 & 19.8 & 9.7 & 17.7 \\
\hline
\end{tabular}




\begin{tabular}{|c|c|c|c|c|c|}
\hline \multirow[b]{2}{*}{ Characteristic } & \multicolumn{4}{|c|}{ Racial/Ethnic Group } & \multirow[b]{2}{*}{$\left(\mathrm{n}=\begin{array}{r}\text { Total } \\
\text { 3014 })\end{array}\right.$} \\
\hline & $\begin{array}{r}\text { Non- } \\
\text { Hispanic } \\
\text { White } \\
(\mathbf{n}=\mathbf{1 8 6 3})\end{array}$ & $\begin{array}{r}\text { Non- } \\
\text { Hispanic } \\
\text { Black } \\
(n=698)\end{array}$ & $\begin{array}{r}\text { Mexican- } \\
\text { Origin } \\
\text { Latina } \\
(\mathbf{n}=\mathbf{3 0 7})\end{array}$ & $\begin{array}{r}\text { Asian/Pacific } \\
\text { Islander } \\
(\mathbf{n}=\mathbf{1 4 6})\end{array}$ & \\
\hline \multicolumn{6}{|l|}{ Inadequate Physical Activity } \\
\hline Neither time point & 26.9 & 22.9 & 25.4 & 26.0 & 26.1 \\
\hline Adolescence only & 13.3 & 12.8 & 17.3 & 14.0 & 13.6 \\
\hline Adulthood only & 31.9 & 30.9 & 31.8 & 36.2 & 31.8 \\
\hline Both time points & 27.9 & 33.5 & 25.5 & 23.8 & 28.6 \\
\hline \multicolumn{6}{|l|}{ Prenatal Health Indicators } \\
\hline Any Cigarette Smoking, $\%$ & 24.5 & 11.5 & 10.1 & 7.4 & 20.7 \\
\hline Any Alcohol Consumption, $\%$ & 5.9 & 3.6 & 9.9 & 9.3 & 5.9 \\
\hline \multicolumn{6}{|l|}{ Entry into Prenatal Care, \% } \\
\hline First trimester & 93.6 & 86.5 & 89.9 & 89.4 & 92.0 \\
\hline Second trimester & 3.8 & 5.2 & 4.0 & 3.9 & 4.1 \\
\hline Third trimester & 1.6 & 4.7 & 4.0 & 1.6 & 2.3 \\
\hline No care & 1.1 & 3.2 & 2.1 & 5.1 & 1.7 \\
\hline
\end{tabular}

Abbreviations: GED, general educational development certificate; LBW, low birth weight; \%, weighted percent; SE, standard error of the mean; SES, socioeconomic status. 
Table 2

Odds of Low vs. Normal Birth Weight from Multinomial Logistic Regression Models, National Longitudinal Study of Adolescent Health, 1994-2008

\begin{tabular}{|c|c|c|c|c|}
\hline \multirow[b]{2}{*}{ Characteristic } & \multicolumn{4}{|c|}{ LBW } \\
\hline & $\begin{array}{l}\text { Model 1: } \\
\text { Crude OR } \\
(95 \% \text { CI) }\end{array}$ & $\begin{array}{c}\text { Model 2: } \\
\text { Adjusted OR } b \\
(95 \% \mathrm{CI})\end{array}$ & $\begin{array}{c}\text { Model 3: } \\
\text { Adjusted OR }^{c} \\
(95 \% \text { CI })\end{array}$ & $\begin{array}{c}\text { Model 4: } \\
\text { Adjusted OR } d \\
(95 \% \mathrm{CI})\end{array}$ \\
\hline \multicolumn{5}{|l|}{ Race/Ethnicity } \\
\hline Non-Hispanic White & 1.00 [Referent] & $1.00[$ Referent $]$ & 1.00 [Referent] & 1.00 [Referent] \\
\hline Non-Hispanic Black & $1.91(1.25-2.90)$ & $1.92(1.20-3.07)$ & $2.17(1.33-3.53)$ & $2.16(1.31-3.56)$ \\
\hline Mexican-Origin Latina & $1.11(0.56-2.19)$ & $1.12(0.57-2.23)$ & $1.44(0.61-3.39)$ & $1.48(0.62-3.53)$ \\
\hline Asian/Pacific Islander & $1.10(0.36-3.40)$ & $1.16(0.39-3.45)$ & $1.70(0.62-4.66)$ & $1.56(0.61-4.03)$ \\
\hline \multicolumn{5}{|l|}{ Preconception Health Indicators } \\
\hline \multicolumn{5}{|l|}{ Any Cigarette Smoking } \\
\hline Neither time point & & 1.00 [Referent] & 1.00 [Referent] & 1.00 [Referent] \\
\hline Adolescence only & & $1.07(0.50-2.29)$ & $1.14(0.53-2.45)$ & $1.10(0.52-2.32)$ \\
\hline Adulthood only & & $1.11(0.64-1.92)$ & $1.10(0.63-1.94)$ & $1.02(0.52-1.97)$ \\
\hline Both time points & & $1.16(0.64-2.11)$ & $1.19(0.66-2.15)$ & $1.01(0.50-2.03)$ \\
\hline \multicolumn{5}{|l|}{ Heavy Alcohol Consumption } \\
\hline Neither time point & & 1.00 [Referent] & 1.00 [Referent] & 1.00 [Referent] \\
\hline Adolescence only & & $0.77(0.39-1.54)$ & $0.76(0.38-1.54)$ & $0.79(0.39-1.61)$ \\
\hline Adulthood only & & $0.96(0.60-1.55)$ & $0.89(0.55-1.46)$ & $0.92(0.56-1.51)$ \\
\hline Both time points & & $1.25(0.58-2.68)$ & $1.19(0.53-2.65)$ & $1.23(0.53-2.83)$ \\
\hline \multicolumn{5}{|l|}{ Overweight/Obesity } \\
\hline Neither time point & & 1.00 [Referent] & 1.00 [Referent] & 1.00 [Referent] \\
\hline Adolescence only & & $3.42(1.04-11.24)$ & $3.32(0.97-11.31)$ & $3.44(0.99-12.01)$ \\
\hline Adulthood only & & $0.91(0.57-1.43)$ & $0.94(0.58-1.53)$ & $0.92(0.57-1.51)$ \\
\hline Both time points & & $1.18(0.68-2.03)$ & $1.19(0.68-2.09)$ & $1.15(0.65-2.02)$ \\
\hline \multicolumn{5}{|l|}{ Inadequate Physical Activity } \\
\hline Neither time point & & 1.00 [Referent] & 1.00 [Referent] & 1.00 [Referent] \\
\hline Adolescence only & & $1.03(0.52-2.03)$ & $1.09(0.55-2.16)$ & $1.08(0.55-2.14)$ \\
\hline Adulthood only & & $1.07(0.65-1.77)$ & $1.12(0.67-1.86)$ & $1.12(0.67-1.87)$ \\
\hline Both time points & & $1.26(0.75-2.12)$ & $1.32(0.78-2.21)$ & $1.32(0.79-2.22)$ \\
\hline \multicolumn{5}{|l|}{ Potential Confounders } \\
\hline Age & & & $0.99(0.91-1.07)$ & $0.99(0.91-1.08)$ \\
\hline \multicolumn{5}{|l|}{ Parity } \\
\hline Nulliparous & & & 1.00 [Referent] & $1.00[$ Referent $]$ \\
\hline Parous & & & $0.65(0.43-0.99)$ & $0.63(0.41-0.96)$ \\
\hline \multicolumn{5}{|l|}{ Nativity } \\
\hline Foreign-born to foreign-born parent & & & $0.53(0.13-2.20)$ & $0.58(0.14-2.40)$ \\
\hline Native-born to foreign-born parent & & & $0.95(0.35-2.56)$ & $1.02(0.37-2.81)$ \\
\hline Native-born to native-born parent & & & $1.00[$ Referent $]$ & 1.00 [Referent] \\
\hline Childhood SES & & & & \\
\hline
\end{tabular}

Womens Health Issues. Author manuscript; available in PMC 2015 January 01. 


\begin{tabular}{|c|c|c|c|c|}
\hline \multirow[b]{2}{*}{ Characteristic } & \multicolumn{4}{|c|}{ LBW } \\
\hline & $\begin{array}{l}\text { Model 1: } \\
\text { Crude OR } \\
\text { (95\% CI) }\end{array}$ & $\begin{array}{l}\text { Model 2: } \\
\text { Adjusted OR }^{b} \\
(95 \% \text { CI })\end{array}$ & $\begin{array}{c}\text { Model 3: } \\
\text { Adjusted OR }^{c} \\
\text { (95\% CI) }\end{array}$ & $\begin{array}{l}\text { Model 4: } \\
\text { Adjusted OR }^{d} \\
\text { (95\% CI })\end{array}$ \\
\hline \multicolumn{5}{|l|}{ Mother's Educational Attainment } \\
\hline Less than high school & & & $0.73(0.41-1.29)$ & $0.70(0.40-1.22)$ \\
\hline GED & & & $0.94(0.41-2.16)$ & $0.91(0.39-2.13)$ \\
\hline High school diploma & & & 1.00 [Referent] & 1.00 [Referent] \\
\hline Some college or trade school & & & $0.95(0.56-1.61)$ & $0.93(0.54-1.59)$ \\
\hline Completed college or more & & & $0.60(0.32-1.10)$ & $0.60(0.32-1.11)$ \\
\hline \multicolumn{5}{|l|}{ Any Household Receipt of Public } \\
\hline Assistance & & & $0.88(0.57-1.37)$ & $0.86(0.55-1.34)$ \\
\hline \multicolumn{5}{|l|}{ Prenatal Health Indicators } \\
\hline Any Cigarette Smoking & & & & $1.34(0.73-2.46)$ \\
\hline Any Alcohol Consumption & & & & $0.49(0.14-1.69)$ \\
\hline \multicolumn{5}{|l|}{ Entry into Prenatal Care } \\
\hline First trimester & & & & $1.00[$ Referent $]$ \\
\hline Second trimester & & & & $1.35(0.61-3.01)$ \\
\hline Third trimester & & & & $1.01(0.31-3.22)$ \\
\hline No care & & & & $2.37(0.88-6.42)$ \\
\hline
\end{tabular}

Abbreviations: CI, confidence interval; GED, general educational development certificate; LBW, low birth weight; OR, odds ratio; SES, socioeconomic status.

${ }^{a}$ ORs are based on weighted data.

${ }^{b}$ Adjusted for preconception health trajectory.

${ }^{c}$ Adjusted for preconception health trajectory, maternal age and parity at birth, nativity, and childhood SES.

${ }^{d}$ Adjusted for preconception health trajectory, maternal age and parity at birth, nativity, childhood SES, prenatal cigarette smoking, prenatal alcohol consumption, and timing of entry into prenatal care. 
Table 3

Odds of Macrosomia vs. Normal Birth Weight from Multinomial Logistic Regression Models, National Longitudinal Study of Adolescent Health, 1994-2008 ${ }^{a}$

\begin{tabular}{|c|c|c|c|c|}
\hline \multirow[b]{2}{*}{ Characteristic } & \multicolumn{4}{|c|}{ Macrosomia } \\
\hline & $\begin{array}{l}\text { Model 1: } \\
\text { Crude OR } \\
\text { (95\% CI) }\end{array}$ & $\begin{array}{c}\text { Model 2: } \\
\text { Adjusted OR } b \\
(95 \% \text { CI })\end{array}$ & $\begin{array}{c}\text { Model 3: } \\
\text { Adjusted OR } c \\
(95 \% \text { CI })\end{array}$ & $\begin{array}{c}\text { Model 4: } \\
\text { Adjusted OR } d \\
(95 \% \text { CI })\end{array}$ \\
\hline \multicolumn{5}{|l|}{ Race/Ethnicity } \\
\hline Non-Hispanic White & 1.00 [Referent] & $1.00[$ Referent $]$ & 1.00 [Referent] & 1.00 [Referent] \\
\hline Non-Hispanic Black & $0.73(0.35-1.53)$ & $0.66(0.32-1.38)$ & $0.73(0.37-1.45)$ & $0.68(0.36-1.27)$ \\
\hline Mexican-Origin Latina & $0.68(0.36-1.31)$ & $0.62(0.32-1.20)$ & $1.02(0.47-2.22)$ & $0.98(0.45-2.16)$ \\
\hline Asian/Pacific Islander & $0.29(0.14-0.58)$ & $0.30(0.15-0.61)$ & $0.51(0.24-1.05)$ & $0.51(0.25-1.06)$ \\
\hline \multicolumn{5}{|l|}{ Preconception Health Indicators } \\
\hline \multicolumn{5}{|l|}{ Any Cigarette Smoking } \\
\hline Neither time point & & 1.00 [Referent] & 1.00 [Referent] & 1.00 [Referent] \\
\hline Adolescence only & & $0.73(0.40-1.31)$ & $0.76(0.42-1.41)$ & $0.82(0.44-1.53)$ \\
\hline Adulthood only & & $0.97(0.55-1.71)$ & $1.02(0.60-1.73)$ & $1.21(0.72-2.05)$ \\
\hline Both time points & & $0.83(0.50-1.35)$ & $0.84(0.52-1.34)$ & $1.11(0.68-1.82)$ \\
\hline \multicolumn{5}{|l|}{ Heavy Alcohol Consumption } \\
\hline Neither time point & & 1.00 [Referent] & 1.00 [Referent] & 1.00 [Referent] \\
\hline Adolescence only & & $0.87(0.53-1.44)$ & $0.86(0.51-1.45)$ & $0.80(0.46-1.39)$ \\
\hline Adulthood only & & $0.99(0.63-1.56)$ & $0.99(0.63-1.57)$ & $1.02(0.64-1.62)$ \\
\hline Both time points & & $1.13(0.53-2.41)$ & $1.08(0.50-2.36)$ & $1.03(0.48-2.21)$ \\
\hline \multicolumn{5}{|l|}{ Overweight/Obesity } \\
\hline Neither time point & & 1.00 [Referent] & $1.00[$ Referent $]$ & $1.00[$ Referent $]$ \\
\hline Adolescence only & & $0.26(0.03-2.19)$ & $0.26(0.03-2.31)$ & $0.29(0.03-2.46)$ \\
\hline Adulthood only & & $1.69(1.10-2.60)$ & $1.72(1.15-2.58)$ & $1.74(1.16-2.61)$ \\
\hline Both time points & & $1.28(0.78-2.09)$ & $1.37(0.84-2.23)$ & $1.41(0.87-2.27)$ \\
\hline \multicolumn{5}{|l|}{ Inadequate Physical Activity } \\
\hline Neither time point & & 1.00 [Referent $]$ & 1.00 [Referent] & $1.00[$ Referent $]$ \\
\hline Adolescence only & & $1.12(0.64-1.96)$ & $1.16(0.66-2.05)$ & $1.15(0.65-2.03)$ \\
\hline Adulthood only & & $0.73(0.41-1.29)$ & $0.73(0.41-1.32)$ & $0.74(0.41-1.33)$ \\
\hline Both time points & & $0.89(0.53-1.51)$ & $0.87(0.51-1.50)$ & $0.87(0.50-1.51)$ \\
\hline \multicolumn{5}{|l|}{ Potential Confounders } \\
\hline Age & & & $1.00(0.90-1.11)$ & $0.99(0.90-1.09)$ \\
\hline \multicolumn{5}{|l|}{ Parity } \\
\hline Nulliparous & & & 1.00 [Referent] & 1.00 [Referent] \\
\hline Parous & & & $1.04(0.72-1.49)$ & $1.09(0.76-1.55)$ \\
\hline \multicolumn{5}{|l|}{ Nativity } \\
\hline Foreign-born to foreign-born parent & & & $0.58(0.14-2.44)$ & $0.55(0.13-2.36)$ \\
\hline Native-born to foreign-born parent & & & $0.55(0.24-1.26)$ & $0.54(0.24-1.24)$ \\
\hline Native-born to native-born parent & & & 1.00 [Referent] & 1.00 [Referent] \\
\hline Childhood SES & & & & \\
\hline
\end{tabular}

Womens Health Issues. Author manuscript; available in PMC 2015 January 01. 


\begin{tabular}{|c|c|c|c|c|}
\hline \multirow[b]{2}{*}{ Characteristic } & \multicolumn{4}{|c|}{ Macrosomia } \\
\hline & $\begin{array}{l}\text { Model 1: } \\
\text { Crude OR } \\
\text { (95\% CI) }\end{array}$ & $\begin{array}{c}\text { Model 2: } \\
\text { Adjusted OR }^{b} \\
\text { (95\% CI) }^{\text {(95\% }}\end{array}$ & $\begin{array}{c}\text { Model 3: } \\
\text { Adjusted OR }^{c} \\
\text { (95\% CI) }\end{array}$ & $\begin{array}{c}\text { Model 4: } \\
\text { Adjusted OR }^{d} \\
\text { (95\% CI })^{\text {(95\% }}\end{array}$ \\
\hline \multicolumn{5}{|l|}{ Mother's Educational Attainment } \\
\hline Less than high school & & & $0.50(0.27-0.92)$ & $0.52(0.28-0.98)$ \\
\hline GED & & & $0.87(0.36-2.15)$ & $0.92(0.36-2.38)$ \\
\hline High school diploma & & & $1.00[$ Referent $]$ & 1.00 [Referent] \\
\hline Some college or trade school & & & $0.75(0.44-1.27)$ & $0.78(0.46-1.32)$ \\
\hline Completed college or more & & & $0.95(0.51-1.76)$ & $0.96(0.51-1.80)$ \\
\hline \multicolumn{5}{|l|}{ Any Household Receipt of Public } \\
\hline Assistance & & & $0.75(0.44-1.28)$ & $0.78(0.45-1.33)$ \\
\hline \multicolumn{5}{|l|}{ Prenatal Health Indicators } \\
\hline Any Cigarette Smoking & & & & $0.49(0.27-0.87)$ \\
\hline Any Alcohol Consumption & & & & $1.15(0.50-2.67)$ \\
\hline \multicolumn{5}{|l|}{ Entry into Prenatal Care } \\
\hline First trimester & & & & 1.00 [Referent] \\
\hline Second trimester & & & & $0.60(0.21-1.69)$ \\
\hline Third trimester & & & & $2.23(0.82-6.05)$ \\
\hline No care & & & & $0.42(0.08-2.25)$ \\
\hline
\end{tabular}

Abbreviations: CI, confidence interval; GED, general educational development certificate; OR, odds ratio; SES, socioeconomic status.

${ }^{a}$ ORs are based on weighted data.

${ }^{b}$ Adjusted for preconception health trajectory.

${ }^{c}$ Adjusted for preconception health trajectory, maternal age and parity at birth, nativity, and childhood SES.

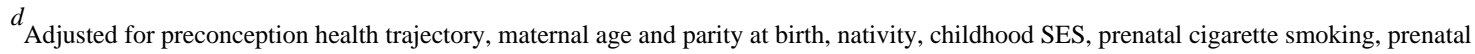
alcohol consumption, and timing of entry into prenatal care. 
Table 4

Odds of LBW or Macrosomia vs. Normal Birth Weight in Multinomial Logistic Regression Models Evaluating Effect Modification, National Longitudinal Study of Adolescent Health, 1994-2008 ${ }^{a}$

\begin{tabular}{|lcc|}
\hline & $\begin{array}{c}\text { LBW } \\
\text { Adjusted OR } \\
(\mathbf{9 5 \%} \mathbf{~ C I})\end{array}$ & $\begin{array}{c}\text { Macrosomia } \\
\text { Adjusted OR } \\
\mathbf{( 9 5 \% ~ C I ) ~}\end{array}$ \\
\hline Race/Ethnicity & $1.00[$ Referent] & 1.00 [Referent] \\
Non-Hispanic White & $3.58(1.65-7.78)$ & $0.31(0.12-0.81)$ \\
Non-Hispanic Black & $1.18(0.22-6.30)$ & $1.31(0.29-5.84)$ \\
Mexican-Origin Latina & $1.62(0.53-4.92)$ & $0.58(0.30-1.13)$ \\
Asian/Pacific Islander & & \\
Overweight/Obesity & $1.00[$ Referent] & $1.00[$ Referent] \\
Neither time point & $3.38(0.77-14.88)$ & $0.23(0.30-1.79)$ \\
Adolescence only & $0.93(0.51-1.71)$ & $1.66(0.95-2.89)$ \\
Adulthood only & $1.75(0.96-3.20)$ & $1.53(0.85-2.74)$ \\
Both time points & & \\
Race/Ethnicity*Overweight/Obesity ${ }^{c}$ & & \\
Black*Adolescence only & $0.23(0.01-3.63)$ & $4.43 * 10^{-8}\left(2.14 * 10^{-9}-9.17 * 10^{-7}\right)$ \\
Black*Adulthood only & $0.56(0.15-2.11)$ & $3.83(1.02-14.36)$ \\
Black*Both time points & $0.27(0.08-0.99)$ & $2.32(0.51-10.56)$ \\
Latina*Adolescence only & $2.29(0.08-68.08)$ & $1.96 * 10^{-10}\left(2.33^{*} 10^{-12}-1.64 * 10^{-8}\right)$ \\
Latina*Adulthood only & $1.21(0.17-8.58)$ & $0.71(0.07-7.05)$ \\
Latina*Both time points & $0.92(0.13-6.32)$ & $0.99(0.14-6.81)$ \\
\hline
\end{tabular}

Abbreviations: CI, confidence interval; LBW, low birth weight; OR, odds ratio.

${ }^{a}$ ORs are based on weighted data.

${ }^{b}$ Adjusted for maternal age and parity at birth, nativity, and childhood socioeconomic status.

${ }^{c}$ Interaction terms for Asian/Pacific Islanders could not be generated due to cell sparseness. 